\title{
Importance of ancillary properties of $\beta$ blockers in angina: a study of celiprolol and atenolol
}

\author{
JAMES M MCLENACHAN, JOHN T WILSON, HENRY J DARGIE \\ From the Department of Cardiology, Western Infirmary, Glasgow
}

SUMMARY Celiprolol $(400 \mathrm{mg})$ and atenolol $(100 \mathrm{mg})$ were given once a day to 16 patients with stable angina pectoris in a double blind placebo controlled crossover study. Celiprolol produced less suppression of heart rate both at rest and during exercise than atenolol. Both drugs were equally effective in reducing the frequency of angina and in delaying the onset of ischaemia during exercise. Radionuclide ventriculography showed that atenolol but not celiprolol lowered cardiac output at rest and during exercise.

Thus the ancillary properties of celiprolol, including partial $\beta_{2}$ agonist activity and direct vasodilating activity, have detectable effects on cardiac function that may be beneficial in patients with angina.

The notable success of $\beta$ adrenoceptor antagonists in the treatment of myocardial ischaemia in patients with coronary heart disease reflects the fact that effort is the main stimulus to the development of such ischaemia. There are some disadvantages associated with the principal therapeutic action of $\beta$ blockade, which is suppression of the increase in heart rate and contractility that normally accompanies exercise. ${ }^{1}$ These include an increase in left ventricular volume, which is energy wasting, and a reduction in cardiac output during exercise. Thus the interest in $\beta$ blockers with ancillary properties that confer a more favourable haemodynamic profile while retaining the beneficial effect on myocardial ischaemia.

Celiprolol is a new $\beta_{1}$ selective adrenoceptor antagonist with partial agonist effects at the $\beta_{2}$ receptor and direct vasodilating activity. It is orally active, undergoes minimal hepatic metabolism, and is active for at least 24 hours when given in a dose of $400 \mathrm{mg}^{2}$

We compared the effects of a daily dose of celiprolol $(400 \mathrm{mg})$ with that of atenolol $(100 \mathrm{mg})$ on angina frequency, effort capacity, and indices of myocardial ischaemia and function at rest and during dynamic exercise in a double blind randomised crossover study of 16 patients with stable angina pectoris.

Requests for reprints to Dr Henry J Dargie, Department of Cardiology, Western Infirmary, Glasgow G11 6NT.

Accepted for publication 14 December 1987

\section{Patients and methods}

\section{PATIENTS}

We studied 16 patients (14 men, two women; age range 28-69 years) with stable effort induced angina pectoris. Three had a previous history of myocardial infarction (all $Q$ wave infarcts); none had sustained an infarct within six months of entry to the study. Patients with evidence of heart failure were excluded and the three patients with previous myocardial infarction all had values for resting left ventricular ejection fractions of $>40 \%$. All 16 had angiographically proven coronary artery disease and a positive treadmill exercise test showing horizontal ST segment depression of at least $1 \mathrm{~mm}$ during exercise.

\section{STUDY DESIGN}

All antianginal treatment, except for glyceryl trinitrate was stopped over a run in period of one week. A single blind placebo period of one week was followed by two double blind treatment periods, each lasting two weeks, during which the patients were treated with atenolol $(100 \mathrm{mg})$ and celiprolol $(400 \mathrm{mg})$ once a day in random order. Assessments were made at the end of the placebo phase (day 7) and at the end of each two week treatment period (days 21 and 35). Exercise testing was carried out approximately six to eight hours after the last oral dose and a recovery period of at least one hour was allowed between the two exercise tests. 


\section{ASSESSMENTS}

The following assessments were made:

Angina frequency and glyceryl trinitrate consumption Diary cards were issued together with a supply of glyceryl trinitrate and patients were asked to record episodes of angina and the number of glyceryl trinitrate tablets they took. Angina frequency and consumption of glyceryl trinitrate were analysed for the week before exercise testing in each of the three phases (that is days $0-7,14-21$, and 28-35).

\section{Treadmill exercise testing}

Heart rate and blood pressure were recorded before exercise in recumbent and standing patients. Symptom limited exercise testing was then performed with a Marquette CASE II system according to a modified Bruce protocol.

\section{Radionuclide ventriculography}

First pass radionuclide ventriculography (technetium-99m) was carried out with a Baird Atomic multi-crystal gammacamera both at rest and during upright bicycle exercise. Patients were exercised to a maximum during the single blind placebo phase and then to that same workload during the two treatment periods. One operator (JTW) did the analysis with standard software. Cardiac output was calculated from the product of heart rate, ejection fraction, and left ventricular end diastolic volume.

\section{Statistical analysis}

Results are given as mean (SE). The statistical significance of differences between treatments was measured by Student's $t$ test for paired data. Appropriate correction was made for multiple comparisons (Bonferroni). Because three comparisons were made for most variables (placebo vs atenolol, placebo vs celiprolol, and atenolol vs celiprolol), significance was assumed at the level of $p<0.02$.

\section{Results}

\section{ANGINA FREQUENCY}

Both atenolol and celiprolol reduced angina frequency significantly more than placebo (table 1); there was no difference between the two active drugs. Glyceryl trinitrate consumption was not significantly reduced by either drug.

Table 1 Angina frequency and consumption of glyceryl trinitrate (GTN) (mean (SE))

\begin{tabular}{llll}
\hline & Placebo & Atenolol & Celiprolol \\
\hline Anginal episodes per week & $10(2)$ & $5(1)^{\star}$ & $6(1)^{\star}$ \\
GTN consumed per week & $8(2)$ & $5(2)$ & $6(1)$ \\
\hline${ }^{\star} \mathrm{p}<0.02$, difference between placebo and drug. &
\end{tabular}

${ }^{\star} \mathrm{p}<0.02$, difference between placebo and drug.
Table 2 Effects of atenolol and celiprolol on treadmill exercise testing (mean ( $S E)$ )

\begin{tabular}{|c|c|c|c|}
\hline & Placebo & Atenolol & Celiprolol \\
\hline $\begin{array}{l}\text { Exercise time (s) } \\
\text { Maximum ST depression } \\
(\mathrm{mm})\end{array}$ & $\begin{array}{l}635(48) \\
2 \cdot 4(0 \cdot 3)\end{array}$ & $\begin{aligned} & 727(52) \\
& 1.9(0.3)\end{aligned}$ & $\begin{array}{l}746(49) \\
2 \cdot 1(0 \cdot 3)\end{array}$ \\
\hline $\begin{array}{l}\text { Time to } 1 \mathrm{~mm} \text { ST depression } \\
(\mathrm{min})\end{array}$ & $7 \cdot 4(1 \cdot 0)$ & $10 \cdot 2(1 \cdot 0)^{\star}$ & $9 \cdot 5(1 \cdot 2)^{\star}$ \\
\hline $\begin{array}{l}\text { Double product }(/ 100) \text { at } \\
1 \mathrm{~mm} \text { ST depression }\end{array}$ & $190 \quad(11)$ & $(6) \ddagger$ & 151 \\
\hline
\end{tabular}

${ }^{\star} \mathrm{p}<0.02,+\mathrm{p}<0.005, \pm \mathrm{p}<0.001$, difference between placebo and drug.

$\S p<0.01$, difference between atenolol and celiprolol.

EFFECTS ON HEART RATE AND BLOOD PRESSURE The two active drugs differed markedly in theiro effects on heart rate and blood pressure. Whereas. atenolol reduced resting heart rate by about $25 \%$ in both the supine and erect postures (table 2), ${ }_{\circ}^{\mathrm{c}}$ celiprolol had no significant effect on resting heart rate. Atenolol significantly reduced systolic blood $\vec{c}$ pressure in both lying and standing patients and also reduced diastolic pressure while the patient was ${ }^{\Phi}$ standing; celiprolol had less effect on resting blood $\overrightarrow{0}$ pressure and significantly reduced only standing diastolic pressure (table 2).

When patients were exercising on the treadmill both drugs significantly suppressed the tachycardia and the increase in blood pressure that occurredo during exercise (figs 1 and 2). For simplicity, only the $p$ values referring to differences between atenolol and $\overrightarrow{\vec{A}}$ celiprolol are shown. When patients were on atenololo음 the curve relating heart rate to exercise time generally paralleled the placebo curve, heart rates being approximately $25 \%$ lower at each stage of exercise on atenolol. When patients were treated with celiprolol, $\mathbb{\bigotimes}$ the curve relating heart rate and exercise time was? flatter (fig 1); thus celiprolol had little effect on $\frac{}{3}$

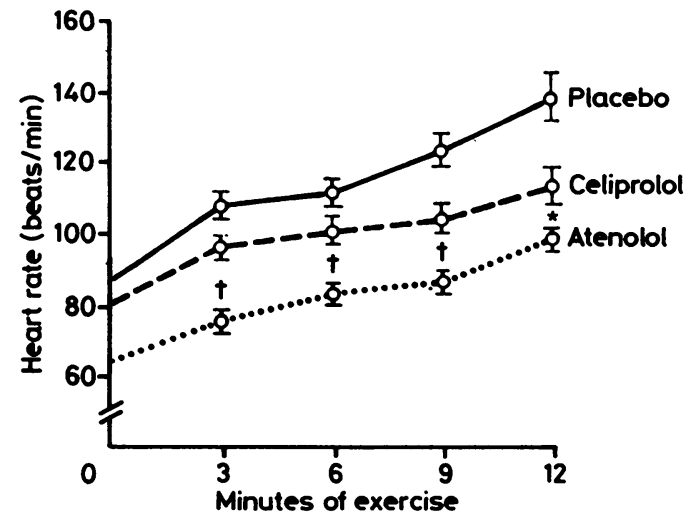

Fig 1 Heart rate (mean ( $S E$ )) during treadmill exercise testing on placebo, atenolol, and celiprolol. Symbols refer to differences between atenolol and celiprolol $\left({ }^{\star} p<0.02\right.$, $\dagger_{p}<0.005$ ). 


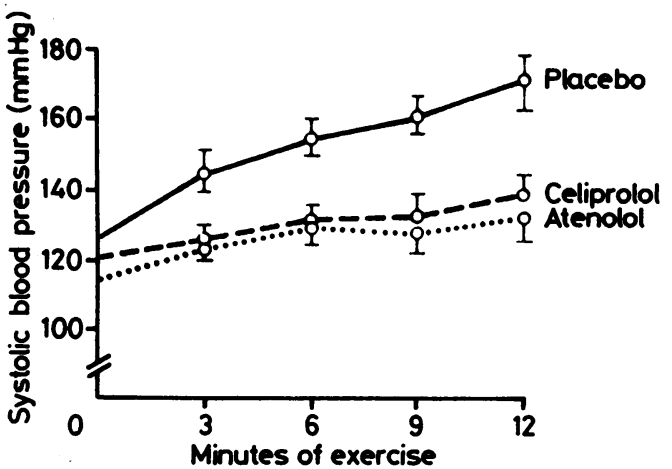

Fig 2 Systolic blood pressure (mean ( $S E$ )) during treadmill exercise testing on placebo, atenolol, and celiprolol. There were no significant differences between atenolol and celiprolol.

resting heart rate but did suppress heart rate as exercise progressed. Even at peak exercise, however, heart rate was significantly higher on celiprolol than on atenolol (120 (4) beats per minute vs 105 (4) beats per minute, $\mathrm{p}<0.005$ ).

The rise in systolic pressure on both drugs was lower than that on placebo, but there were no significant differences between the two drugs (fig 2).

\section{EXERCISE CAPACITY AND}

\section{ELECTROCARDIOGRAPHIC EVIDENCE OF}

MYOCARDIAL ISCHAEMIA

Mean exercise time on placebo was 635 (48) seconds. Exercise time was prolonged, but not significantly, by celiprolol $(746(49) \mathrm{s}, \mathrm{p}=0.031$ vs placebo) and by atenolol (727 (52) s, p > 0.10) (table 3). Maximum ST segment depression was not reduced by either drug (table 3 ), but both significantly delayed the onset of $1 \mathrm{~mm}$ ST segment depression; there was no significant difference between atenolol and celiprolol. The double product (heart rate $\times$ systolic blood pressure) at the onset of $1 \mathrm{~mm} \mathrm{ST} \mathrm{depression}$ was significantly lower on both drugs than on placebo and significantly higher on celiprolol than on atenolol (table 3).

Table 3 Effect of atenolol and celiprolol on resting heart rate and blood pressure (mean ( $S E)$ )

\begin{tabular}{lrrr}
\hline & Placebo & Atenolol & Celiprolol \\
\hline Lying: & & & \\
Heart rate (beats/min) & $80(2)$ & $58(2) \dagger$ & $74(3) \ddagger$ \\
Systolic BP(mm Hg) & $131(5)$ & $117(3)^{\star}$ & $126(4)$ \\
Diastolic BP(mm Hg) & $88(3)$ & $75(3)$ & $82(3)$ \\
Standing: & $87(3)$ & $64(2) \dagger$ & $81(3) \ddagger$ \\
Heart rate (beats/min) & $125(5)$ & $113(3)^{\star}$ & $119(4)$ \\
Systolic BP(mm Hg) & $87(3)$ & $7(2)^{\star}$ & $81(3)^{\star}$ \\
Diastolic BP (mm Hg) & 87
\end{tabular}

${ }^{*} \mathrm{p}<0.02, \dagger \mathrm{p}<0.001$, difference between placebo and drug. tp $<0.001$, difference between atenolol and celiprolol.
Table 4 Effects of atenolol and celiprolol on left ventricular function (mean (SE))

\begin{tabular}{lrcc}
\hline & Placebo & Atenolol & Celiprolol \\
\hline Rest EF (\%) & $55(2)$ & $53(2)$ & $52(2)$ \\
Exercise EF (\%) & $43(3)$ & $51(3) \dagger$ & $49(1)^{\star}$ \\
Change in EF & $-13(3)$ & $-2(3)^{\star}$ & $-3(2) \ddagger$ \\
\hline
\end{tabular}

${ }^{\star} p<0.02,+p<0.005, \neq p<0.001$, difference between placebo and drug.

$\mathrm{EF}$, ejection fraction.

\section{EFFECTS ON LEFT VENTRICULAR FUNCTION}

The resting ejection fraction was $55(2) \%$ on placebo; during bicycle exercise this fell to $43(3) \%(p<0.01)$. Atenolol and celiprolol had no effect on resting ejection fraction but both significantly ameliorated the fall in ejection fraction with exercise (table 4). Compared with placebo, atenolol but not celiprolol reduced cardiac output both at rest and during exercise (fig 3).

\section{SIDE EFFECTS}

No serious side effects were reported. One patient complained of lightheadedness while on atenolol and on celiprolol and one experienced fatigue on both atenolol and placebo.

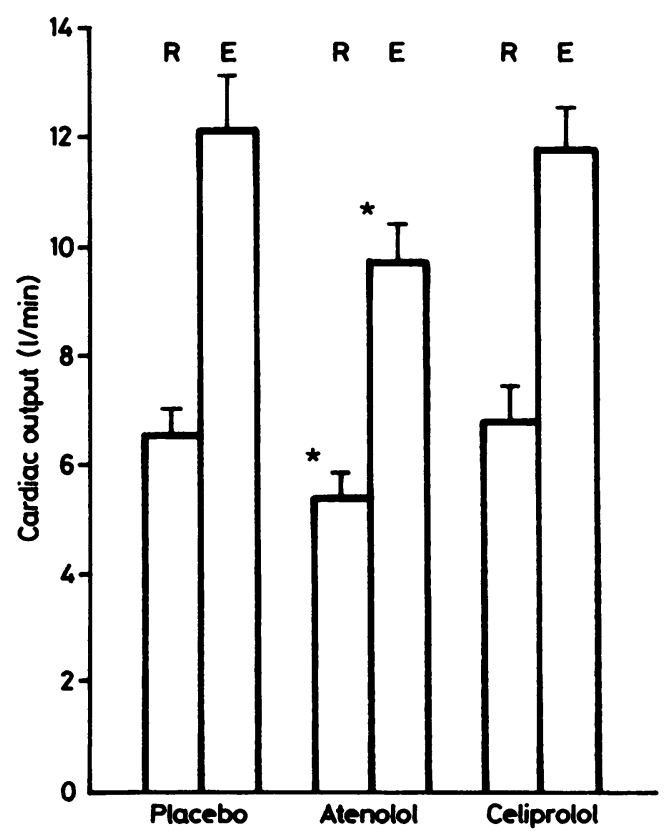

Fig 3 Cardiac output ( $l / \mathrm{min}$ ) at rest $(R)$ and during exercise $(E)$ for the three treatment periods. Compared with placebo, cardiac output was significantly reduced $(p<0.02)$ both at rest and during exercise by atenolol but not by celiprolol. 
The low frequency of side effects may reflect the fact that most of the patients had been treated with, and were tolerant of, $\beta$ blockers before they joined the study.

\section{Discussion}

The major therapeutic action of conventional $\beta$ blockers in angina pectoris is the suppression of exercise induced tachycardia, which leads to a reduction in myocardial oxygen requirement. $\beta$ Blockers with intrinsic sympathomimetic activity produce less of a reduction in heart rate at rest and during exercise but may be less effective antianginal agents than $\beta$ blockers without this property. ${ }^{3}$ Figure 1 shows that celiprolol acts like a $\beta$ blocker with intrinsic sympathomimetic activity; it had little effect on resting heart rate but produced considerable blunting of the exercise induced rise in heart rate. At peak exercise, heart rate and double product were significantly higher on celiprolol than on atenolol, yet both drugs were equally effective at reducing myocardial ischaemia during exercise as shown by electrocardiographic indices. Subjective testing showed that both drugs produced an equal reduction in angina frequency in keeping with previous studies that showed the antianginal efficacy of celiprolol. ${ }^{45}$ There were, however, striking differences in their respective haemodynamic profiles, suggesting different mechanisms of action.

The product of heart rate and systolic blood pressure correlates with oxygen consumption. ${ }^{6}$ Glyceryl trinitrate relieves angina by lowering the rate-pressure product, ${ }^{7}$ but if the workload is further increased to raise this product to the baseline level, pain still occurs. The administration of $\beta$ blockers, however, lowers the rate-pressure product at the onset of ischaemia by about $30 \%{ }^{8}$ suggesting an adverse effect on myocardial oxygen consumption for the same amount of cardiac work at a given pressure. ${ }^{9}$ Table 3 shows that the rate-pressure product achieved for a similar degree of myocardial ischaemia on celiprolol was significantly higher than that on atenolol. The rate-pressure product on both drugs was lower than on placebo. This suggests that the ancillary properties of celiprolol have a beneficial effect on myocardial oxygen balance, either by increasing myocardial oxygen supply or by reducing demand. Several properties of celiprolol may contribute to this effect.

In patients with coronary artery disease drugs with intrinsic sympathomimetic activity produce less of an increase, or even a small fall, in systemic vascular resistance than drugs without such activity. ${ }^{10}$ Thus the reduction in diastolic blood pressure on celiprolol might be explained by a fall in systemic vascular resistance whereas the reduction on atenolol probably reflects the fall in cardiac output. In addition, celiprolol seems to have a direct vasodilator action since its vasodilator activity is not abolished by blockade of $\beta_{2}$ agonist effects by propranolol. ${ }^{11}$ Thus a reduction in afterload by intrinsic sympathomimetic activity and vasodilator activity might reduce oxygen demand and improve cardiac pumping in patients with ischaemic heart disease. Furthermore, in animal studies celiprolol had a positive inotropic effect that was not due solely to $\beta_{2}$ agonism as this effect also persisted in the presence of propranolol. ${ }^{12}$

Measurement of ejection fraction does not allow us to determine whether an observed rise is caused by increased contractility or to a change in loading conditions. Thus the ability to maintain a higher ejection fraction and cardiac output at a higher heart rate on celiprolol than on atenolol could be explained either by an increase in myocardial contractility or by afterload reduction mediated by both $\beta_{2}$ agonism and direct vasodilator activity. Whether these ancillary actions of celiprolol will be associated with a reduction in side effects of $\beta$ blockade, particularly fatigue, remains to be seen.

In conclusion, celiprolol is an effective antianginal agent that seems to be well tolerated. It has less effect on heart rate than atenolol and does not reduce cardiac output either at rest or during exercise. These effects are probably related to its ancillary properties including $\beta_{2}$ agonism and direct vasodilator activity, which may be beneficial in ischaemic heart disease.

J M McL was supported by a British Heart Foundation Junior Research Fellowship.

\section{References}

1 Taylor SH. Beta-blocking drugs and myocardial function. J Cardiovasc Pharmacol 1986;8(suppl 4): S75-82.

2 Caruso FS, Doshan HD, Hernandez PH, Costello R, Applin W, Neiss ES. Celiprolol: pharmacokinetics and duration of pharmacodynamic activity. $\mathrm{Br} \mathrm{J} \mathrm{Clin}$ Pract 1985;39(suppl 40):12-6.

3 Magnani B, Mantovani B, Brancaleoni M, Gubbell S, Ambrosioni E. Cardioselectivity and partial agonist activity in the antianginal efficacy of the $\beta$-adrenoceptor antagonists: a clinical comparison between atenolol and pindolol. Drugs 1983;25(suppl 2):166-71.

4 Eff J, Godfrey J, Garutti R, Capone P. Celiprolol in angina pectoris: a controlled study. $J$ Cardiovasc Pharmacol 1986;8(suppl 4):S132-4.

5 Jackson NC, Lee PS, Taylor SH. A single blind randomized comparison of the 24-h antianginal efficacy of celiprolol versus atenolol. $J$ Cardiovasc 
Pharmacol 1986;8(suppl 4):S145-7.

6 Nelson RR, Gobel FL, Jorgensen CR, Wang K, Wang Y, Taylor HL. Haemodynamic predictors of myocardial oxygen consumption during static and dynamic exercise. Circulation 1974;50:1179-89.

7 Robinson BF. Mode of action of nitroglycerin in angina pectoris. Correlation between haemodynamic effects during exercise and prevention of pain. Br Heart J 1968;30:295-302.

8 Battock DJ, Alvarez H, Chidsey CA. Effects of propranolol and isosorbide dinitrate on exercise performance and adrenergic activity in patients with angina pectoris. Circulation 1969;39:157-69.
9 Robinson BF. The mode of action of beta-antagonists in angina pectoris. Postgrad Med J 1971;47(suppl January):41-3.

10 Taylor SH, Silke B. Coronary insufficiency and beta blockade. J Cardiovasc Pharmacol 1985;7:S80-9.

11 Shlevin HH, Barrett JA, Smith RD, Wolf PS. Celiprolol $\mathrm{HCl}$ : myocardial contractile and beta adrenoreceptor antagonist effects in anaesthetized dogs [Abstract]. Pharmocologist 1982;24:541.

12 Shlevin HH, Barrett JA, Thomson GF, Wolf PS, Pruss TP, Smith RD. Celiprolol HCl: propranolol-insensitive cardiostimulatory effects in anaesthetized dogs [Abstract]. Pharmacologist 1983;25:263. 